ISSN: $2338-4794$

Vol.6. No. 2 Mei-Agustus 2018

\title{
E-COMMERCE: STUDI TENTANG BELANJA ONLINE DI INDONESIA
}

\author{
Wiwik Rachmarwi *) \\ *) Dosen Program Studi Manajemen FE UNKRIS \\ Alamat: Kampus UNKRIS, Jatiwaringin Jakarta Timur \\ E-mail: rachmarwi@gmail.com, wiwikrachmarwi@unkris.ac.id
}

\begin{abstract}
The purpose of this research is to know the potential of the e-commerce industry and to establish preliminary assessment, evaluation and understanding of the characteristics of online shopping in Indonesia which experienced the slowest growth in the last five years. Chi-test tests are used to determine the relationship between current online shoppers and demographic variables. The t-test sample is then used to compare the average difference between the current online buyers and the non-online buyers. It also investigates the influence of factors (demographic profile, previous online shopping experience, perceived benefits, consumer lifestyles, and perceived buyer confidence)
\end{abstract}

Keyword : e-commerce, demography profile, online shopping

\section{PENDAHULUAN}

Perkiraan terbaru oleh Macquarie Bank menunjukkan pasar Indonesia telah tumbuh 60-70 persen setiap tahun sejak 2014 dan akan berkembang dari US \$ 8 miliar pada tahun 2016 menjadi US \$ 60 miliar pada tahun 2020. Hal ini diharapkan dapat menghasilkan peluang baru untuk situs e-commerce dan bisnis mereka. Beberapa faktor telah mendorong kebangkitan industri e-commerce Indonesia. Peningkatan penetrasi smartphone dan internet, investasi asing yang intensif di platform terkemuka, kelas menengah Indonesia yang sedang tumbuh, dan perombakan pembayaran online yang lebih baru-baru ini semuanya berkontribusi terhadap pertumbuhan pasar dan kecanggihan pemain lokal.

Industri e-commerce di Indonesia tidak bisa dipandang sepele. berdasarkan data Ernst \& Young, disimpulkan bahwa pertumbuhan angka penjualan bisnis online di Indonesia meningkat 40 persen. Angka tersebut diperoleh dari 93,4 juta para pengakses internet dan 71 juta pengguna telepon seluler di Indonesia.

Penggunaan internet dan telepon seluler tidak hanya sekedar untuk mencari berbagai informasi dan ngobrol, masyarakat saat kini menjadikan internet terutama e-commerce sebagai bagian dari gaya hidup mereka. Sebagian masyarakat kelas menegah selalu berperilaku konsumtif hal tersebut menjadi alasan kenapa e-commerce di Indonesia diyakini mempunyai potensi besar.

Gambar 1: Transaksi E-commerce Indonesia 2014 - 2018

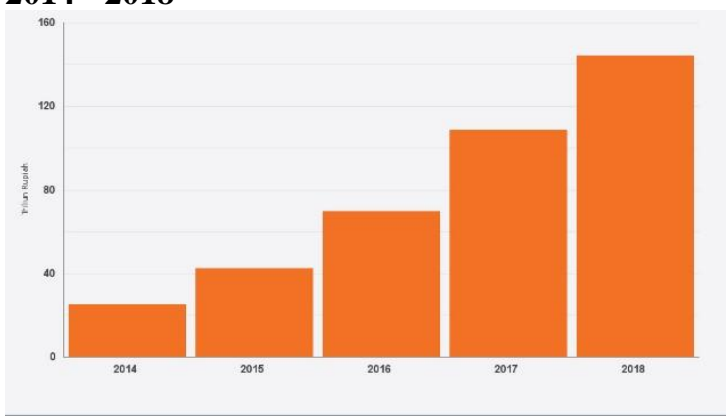

Sumber: Databox

Indonesia telah lama membuntuti rival regionalnya yang lebih besar, Cina 
dan India, dalam hal ukuran pasar ecommerce dan kecanggihan. Tetapi setelah bertahun-tahun mengawasi perusahaan internasional dan lokal bersaing di dua pasar yang lebih besar ke utara, Indonesia sekarang menikmati beberapa sorotan global. Investasi internasional ke pasar mencapai tertinggi sepanjang waktu sebagai jajaran raksasa internet global joki untuk posisi di negara keempat terpadat di dunia.

Gambar 2: Populasi daring dari setiap pasar, bukan populasi totalnya.

\begin{tabular}{|c|c|c|c|c|c|}
\hline Argentina & 1,581 & Ireland & 1,250 & Saudi Arabia & 1,256 \\
\hline Australia & 2,291 & Italy & 2,836 & Singapore & 2,517 \\
\hline Austria & 1,326 & Japan & 1,791 & South Africa & 1,527 \\
\hline Belgium & 1,301 & Kenya & 1,000 & South Korea & 1,251 \\
\hline Brazil & 2,330 & Malaysia & 1,556 & Spain & 2,849 \\
\hline Canada & 2,288 & Mexico & 2,602 & Sweden & 1,292 \\
\hline China & 15,142 & Morocco & 1,000 & Switzerland & 1,265 \\
\hline Egypt & 1,759 & Netherlands & 1,312 & Taiwan & 1,819 \\
\hline France & 3,329 & New Zealand & 1,288 & Thailand & 1,533 \\
\hline Germany & 2,906 & Nigeria & 1,000 & Turkey & 1,576 \\
\hline Ghana & 1,000 & Philippines & 1,561 & UAE & 1,781 \\
\hline Hong Kong & 1,787 & Poland & 1,833 & UK & 7,810 \\
\hline India & 4,063 & Portugal & 1,310 & United States & 16,179 \\
\hline Indonesia & 1,785 & Russia & 2,296 & Vietnam & 1,573 \\
\hline
\end{tabular}

Sumber: GlobalWebIndex's Q1 2018

Kondisi lokal yang kompleks sering mengakibatkan Indonesia menjadi tidak berdomisili oleh perusahaan-perusahaan global yang ingin mengakses pasar konsumen Asia, terutama mengingat ukuran dan kemudahan komparatif menjual produk ke China. Tren positif yang diuraikan di bawah ini menyarankan peninjauan kembali sikap ini dibenarkan.

Penyesuaian akan pertumbuhan teknologi informasi dan komunikasi adalah sebuah keyakinan yang harus dilakukan agar menjadi pemain aktif pada era globalisasi. Potensi ekonomi digital ini perlu dan harus diutamakan sebagai salah satu akar pertumbuhan ekonomi baru yang dapat ditingkatkan lagi. Berdasarkan informasi dari Kemenlu RI di Jakarta, laporan McKinsey Global Institute (2016) dikatakan bahwa ekonomi digital menyumbang kontribusi sebanyak 22 persen akan output ekonomi global. Aplikasi teknologi digital diramalkan bakal meningkatkan PDB global sekitar 2 trilliun dollar AS di tahun 2020.

Akan tetapi, pemakaian ekonomi digital di Indonesia sampai dengan sekarang belum dimanfaatkan secara optimal. Asian Development Bank (2016) menginformasikan bahwa sumbangan ecommerce pada perkembangan ekonomi di Indonesia sekitar kurang dari 1 persen. Hal ini masih rendah jika dibandingkan dengan Tiongkok yang e-commerce-nya berkontribusi hingga 9-10 persen.

Diperlukan roadmap peningkatan ecommerce Indonesia yang sudah dirancang Pemerintah dapat menolong menghasilkan ekosistem yang kondusif agar tercapainya 1000 technopreneurs dan mengangkat angka e-commerce nasional sekitar 130 milliar dollar AS ada tahun 2020. Kerjasama dari semua pihak terkait untuk imlementasi roadmap adalah kunci keberhasilan dari pengembangan e-commerce di Indonesia.

Gambar 3: Roadmap E-commerce Asia Tenggara

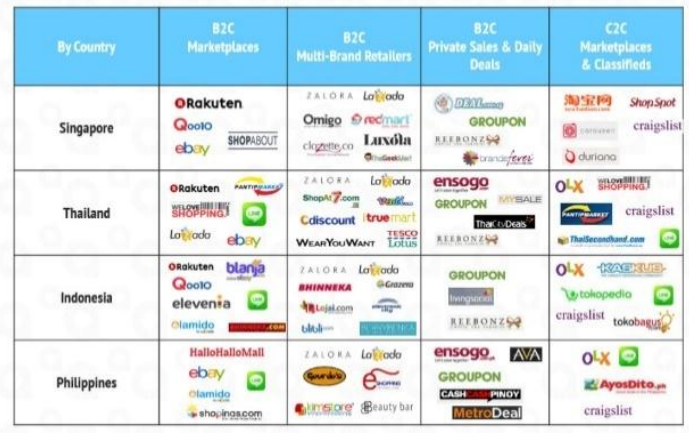

Sumber : www.acommerce.asia 
Pada tingkat internasional, dialog ekonomi digital semakin berkembang, salah satunya pada forum G20, WTO dan APEC. Forum diskusi pada WTO sekarang ini fokus pada masalah penangguhan dikenakannya bea masuk pada bisnis ecommerce juga merupakan tugas bagi semua anggota pada konteks pembicaraan di WTO.

Namun, tampaknya ada kurangnya pemahaman dan pengetahuan tentang sikap konsumen terhadap belanja online. Mengingat bahwa belanja online masih pada tahap awal pengembangan, sedikit yang diketahui tentang sikap konsumen terhadap mengadopsi saluran belanja baru ini dan faktor-faktor yang mempengaruhi sikap mereka terhadapnya (Eastlick dan Lotz, 1999). Hal ini terutama berlaku dalam konteks di Indonesia di mana belanja online masih baru dan konsumen kurang akrab dan sering lebih skeptis terhadap belanja online, tetapi sedikit yang diketahui tentang mereka. Oleh karena itu, penelitian ini bertujuan untuk memeriksa pengguna belanja online saat ini di Indonesia dengan tujuan menetapkan penilaian awal, evaluasi dan pemahaman karakteristik pembeli online di Indonesia

Gambar 4: E-Commerce Paling Populer di Sosial Media

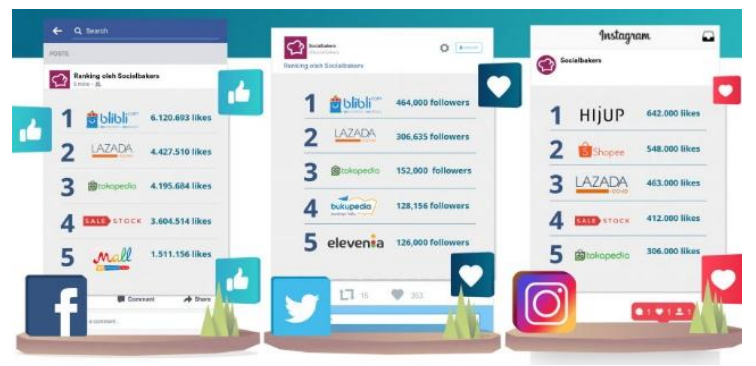

Sumber: iprice

\section{LANDASAN TEORI}

Kemunculan e-commerce bukanlah sesuatu yang baru secara revolusioner seperti yang telah ada selama beberapa waktu (OECD, 1997). Sejak tahun 1970-an dan 1980-an, bisnis telah menyebarkan ecommerce melalui pertukaran data elektronik (EDI) untuk pertukaran komputer-ke-komputer dari dokumen transaksi elektronik standar dalam suatu organisasi atau antarorganisasi menggunakan jaringan bernilai tambah pribadi (VAN) swasta sebagai media komunikasi. Namun, bentuk e-commerce tradisional ini menggunakan jaringan nilai tambah pribadi sebagai media komunikasi yang mahal untuk dipasang dan dipelihara, dan telah menempatkan e-commerce di luar jangkauan dalam banyak bisnis skala kecil dan menengah (Margherio, 1998). Kedatangan penggunaan komersial Internet dan World Wide Web (WWW) telah mendefinisikan e-commerce baru sejak 1993 (Zwass, 1996). Dengan munculnya Internet dan World Wide Web (WWW) sebagai media untuk transaksi komersial, ia telah mendorong e-commerce menjadi sorotan, menjadi fokus utama masyarakat internasional. Internet dan WWW telah membuatnya lebih mudah, lebih sederhana, lebih murah dan mudah diakses untuk bisnis dari semua ukuran dan konsumen untuk berinteraksi dan melakukan transaksi komersial secara elektronik dibandingkan dengan pendekatan tradisional menggunakan jaringan nilai tambah pribadi (Margherio, 1998). Berdasarkan arsitektur jaringan Internet, e-commerce lahir global, di mana batas-batas geografis dan batasbatas politik sangat kecil dalam lingkungan jaringan ini (OECD, 1997). Akibatnya, ecommerce melalui internet secara dramatis mengurangi jarak antara produsen dan konsumen, yang dapat melakukan pembelian secara langsung tanpa melibatkan 'perantara' tradisional seperti penjual, grosir, dan distributor. Meskipun perantara baru diperlukan (misalnya penyedia akses jaringan, sistem 
pembayaran elektronik, dan layanan otentikasi dan sertifikasi), ini jauh lebih sedikit dibandingkan dengan saluran tradisional (Wyckoff, 1997). Elektronik ritel melalui Internet atau belanja online pertama kali dimulai pada tahun 1994 (Hsin, 2000). Ini dianggap sebagai salah satu bentuk pemasaran konsumen langsung dari non-toko ritel menggunakan saluran online. Konsep baru ritel ini telah menarik minat banyak penjual dan pedagang karena pengakuan umum bahwa belanja online akan memantapkan dirinya sebagai saluran alternatif bersama saluran ritel offline tradisional seperti toko ritel fisik (Rowley, 2000). Retailing elektronik terutama dimulai dalam bentuk etalase online tempat produk dari satu pedagang ditawarkan kepada konsumen melalui katalog online. Pedagang cenderung memilih untuk membangun etalase online sebagai metode penjual online ketika nama dan reputasi merek produk sudah dikenal dan dikenal luas di kalangan konsumen. Contoh yang baik adalah The Dell Online Store yang menjual komputer pribadi (The Economist, 1997) ke konsumen di mana saja. Namun, sebagian besar kesesuaian Internet untuk pemasaran tergantung pada karakteristik produk dan layanan yang dipasarkan (Peterson et al., 1997). Menurut sebuah studi oleh Profesor Rajiv Lal dan Asisten Profesor Miklos Sarvary dari Stanford Business School di Palo Alto, California, AS, produk yang dipasarkan melalui Internet dapat diklasifikasikan menjadi dua kelompok (Legard, 1998). Kelompok produk pertama adalah barang-barang yang tidak perlu dilihat langsung oleh konsumen sebelum membeli. Produk-produk ini, yang mencakup segala hal mulai dari komputer hingga compact disc hingga barang kaleng, dapat dievaluasi hanya dengan menggunakan teks, gambar dan informasi digital lainnya yang dapat ditularkan. Kelompok produk ini sangat ideal untuk belanja online di mana Internet dapat melayani fungsi transaksi dan komunikasi yang signifikan (Peterson et al., 1997).

Kelompok produk kedua disebut sebagai 'produk pengalaman', yang mencakup item yang lebih suka dilihat dan disentuh oleh pembeli sebelum membeli, seperti pakaian dan bahan makanan. Grup produk ini tidak cocok untuk belanja daring karena informasi tentang fitur produk mungkin tidak memadai bagi konsumen untuk terlibat dalam transaksi berbasis Internet. Konsumen hanya akan membeli produk tersebut dari Internet setelah mereka mengalaminya (Landry, 1998; Peterson et al., 1997).

Tabel 1: Alasan Mengapa Orang Berbelanja Online

\begin{tabular}{l|l} 
- Menghemat waktu / Kenyamanan & $78 \%$ \\
- Harga lebih baik & $51 \%$ \\
- Lebih banyak pilihan & $43 \%$ \\
- Pengiriman yang lebih mudah & $40 \%$ \\
- Kemampuan untuk menemukan hadiah & $28 \%$ \\
$\quad$ yang lebih dipersonalisasi & \\
- Informasi lebih lanjut tersedia tentang & $20 \%$ \\
- - Lainnya & $8 \%$ \\
\hline
\end{tabular}

Sumber: McGann, "Online Holiday Purchases to Grow Despite Growing Security Concerns", ACNielsen Research, November 30th 2004

Konsumen berbelanja di Internet karena mereka menemukan pilihan mereka meningkat secara dramatis. Mereka memiliki akses ke lebih banyak informasi ketika membuat keputusan pembelian. Konsumen yang sibuk dapat menghemat waktu dan menemukan belanja lebih nyaman karena pedagang online melayani kebutuhan mereka secara individual. Akses informasi yang lebih baik dan lebih besar, dikombinasikan dengan biaya operasi yang lebih rendah untuk banyak bisnis Internet dapat, pada gilirannya, mendorong penurunan harga atau peningkatan kualitas (Margherio, 1998). Konsep "Membawa toko ke pembeli - bukan pembeli ke toko" 
akhirnya juga terwujud. Selain itu, masalah kenyamanan dan kecepatan tampaknya menjadi alasan paling jelas mengapa pembeli lebih menyukai belanja online, berbeda dengan metode belanja tradisional batu bata dan mortir. Konsumen juga telah digambarkan sebagai miskin waktu, sehingga putus asa untuk menghabiskan waktu non-kerja mereka dalam kegiatan rekreasi lebih sebagai argumen untuk pertumbuhan dan keberlanjutan belanja online (Parsons, 2002). Berdasarkan studi yang dilakukan oleh ACNielsen Research, alasan mengapa konsumen berbelanja online melalui Internet ditunjukkan pada Tabel 1 di atas (McGann, 2004). Kenyamanan adalah faktor paling menonjol yang memotivasi konsumen untuk berbelanja online. Waktu, lokasi, dan proses pembelian melalui internet jauh lebih unggul daripada metode tradisional lainnya untuk membeli barang dan jasa (Hanson, 1999). Ketersediaan 24-jam dari etalase online dan aksesibilitas dari hampir semua lokasi menjadikan belanja daring lebih nyaman bagi konsumen dan menyediakan saluran alternatif yang kuat bagi pembeli untuk melakukan pembelian. Faktor dominan kedua yang memengaruhi konsumen untuk berbelanja online adalah harga kompetitif dan penawaran yang ditawarkan oleh penjual online. Alasan paling sederhana bagi konsumen untuk membeli secara online adalah untuk menghemat uang dari harga lebih murah yang ditawarkan oleh penjual online dibandingkan dengan saluran tradisional. Penjual online dapat menawarkan harga yang lebih murah karena menyusutnya biaya pemrosesan informasi, menurunkan biaya operasi dan jangkauan global yang disediakan oleh Internet (Rowley, 2000). Alasan utama lainnya bahwa harga yang lebih murah ditawarkan kepada pembeli online adalah karena tekanan kompetitif, terutama dari penjual online baru. Penjual online baru menggunakan harga sebagai senjata kompetitif utama untuk menarik pelanggan (Hanson, 1999). Faktor dominan ketiga yang memotivasi konsumen online untuk membeli barang dan layanan melalui Internet adalah pilihan yang baik dan ketersediaan pilihan produk yang lebih luas yang ditawarkan oleh penjual online. Penjual online dapat menyediakan beragam dan beragam produk dibandingkan dengan saluran tradisional hanya karena tidak ada batasan ruang fisik pada jumlah produk yang dapat ditampilkan penjual online di etalase online mereka. Misalnya, Barnes \& Noble dan CD Sekarang dapat menawarkan jutaan buku dan judul musik kepada pelanggan di situs web mereka. Selain itu, jumlah toko online yang dapat dikunjungi konsumen secara online jauh melebihi jumlah toko fisik, sehingga memberikan mereka pilihan produk yang lebih luas untuk dipilih. Kemudahan penelitian dalam mengumpulkan informasi produk juga merupakan salah satu faktor yang mempengaruhi konsumen untuk berbelanja online. Di ruang pasar virtual di Internet, pencarian konsumen untuk informasi produk jauh lebih efektif dan efisien dilakukan dibandingkan dengan saluran tradisional. Hal ini dicapai dengan menggunakan browser dan agen pencarian cerdas seperti agen belanja pembanding yang dirancang untuk secara bersamaan mencari dan membandingkan harga produk di beberapa penjual online (Rowley, 2000). Ini membuat proses pembelian di Internet lebih mudah bagi konsumen. Beberapa contoh agen belanja perbandingan yang dipublikasikan dengan baik di Internet adalah Tokopedia, Bukalapak, dan Shopee.

\section{METODE PENELITIAN}

Metode penelitian yang digunakan dalam penelitian ini adalah tipe deskriptif 
dengan menggunakan metode survei kuantitatif. Tujuan utama dari penelitian ini adalah untuk mengetahui hubungan antara variabel, yaitu sikap versus niat pembelian online, sikap versus faktor yang dipilih (demografi, manfaat yang dirasakan, pengalaman pembelian online sebelumnya, gaya hidup konsumen, dan kepercayaan yang dirasakan penjual).

Kuesioner terstruktur digunakan untuk mengumpulkan data yang diperlukan. Ini berfungsi sebagai data primer untuk menjawab pertanyaan dan tujuan penelitian yang berkaitan dengan belanja online di Indonesia. Kuesioner survei terdiri dari 10 bagian yang berbeda, masing-masing berisi pertanyaanpertanyaan ke bagian yang berbeda dari penelitian. Mengingat keterbatasan waktu dan biaya serta besarnya populasi pengguna Internet di Indonesia, kemudahan sampling digunakan untuk mengumpulkan data

\section{HASIL DAN PEMBAHASAN PENELITIAN}

Analisis distribusi frekuensi digunakan untuk memeriksa dan mendeskripsikan profil demografis pengguna belanja online saat ini dengan tujuan menyediakan penilaian awal pembeli online saat ini di Indonesia. Hasil analisis profil demografis ditunjukkan pada Tabel 2.

Table 2: Demographic profile of survey respondent

\begin{tabular}{|lcc|}
\hline Variabel & & Frekuensi \\
Percentase & & \\
\hline Umur (dalam tahun) & & 2 \\
Kurang dari 20 years & 5 & 47.2 \\
21-30 years & 118 & 40.8 \\
31-40 years & 102 & 10 \\
41-50 years & 25 & \\
Gender & & 62 \\
Male & 155 & \\
\hline
\end{tabular}

\begin{tabular}{|lcc|}
\hline Female & 95 & 38 \\
Tingkat Pendidikan & & \\
Sekolah Menengah & 40 & 16 \\
Diploma & 45 & 18 \\
Universitas & 165 & 66 \\
Occupation & & \\
Professiona & 168 & 67.2 \\
Student & 20 & 8 \\
Others & 62 & 24.8 \\
\hline
\end{tabular}

Responden adalah laki-laki sementara $38 \%$ dari responden yang tersisa adalah perempuan. Dalam penelitian ini, responden dikategorikan ke dalam 4 tingkat kelompok usia; kurang dari 20 tahun; 21 hingga 30 tahun; 31 hingga 40 tahun dan 41 hingga 50 tahun. Dari Tabel 3 , mayoritas responden $(47,2 \%)$ jatuh dalam rentang usia antara 21 hingga 30 tahun. Ini diikuti oleh $40,8 \%$ responden dari kategori usia 31 hingga 40 tahun sementara $10 \%$ termasuk dalam kategori usia 41 hingga 50 tahun. Akhirnya, 2\% responden berasal dari kategori kurang dari 20 tahun. Analisis frekuensi digunakan untuk menentukan berbagai metode pembayaran yang terutama digunakan oleh pengguna belanja online dalam melakukan pembayaran untuk pembelian online mereka. Hasil analisis frekuensi diberikan pada Tabel 3.

Table 3: Metode Pembayaran

\begin{tabular}{|lcc|}
\hline Metode Pembayaran & $\begin{array}{c}\text { Frekuensi } \\
\text { N=250 }\end{array}$ & Percentase \\
\hline Transfer Bank & 135 & 54 \\
Cash on delivery (C.O.D) & 70 & 28 \\
Kartu Kredit & 35 & 14 \\
Lainnya & 10 & 4 \\
\hline
\end{tabular}

Hasil pada Tabel 3 menunjukkan bahwa mayoritas konsumen online menggunakan transfer bank (54\%) untuk melakukan pembayaran mereka untuk pembelian online, diikuti oleh cash on delivery (COD) (28\%), kartu kredit dan lainnya dilakukan sangat persentase kecil masing-masing $14 \%$ dan $4 \%$. Analisis nilai rata-rata 
digunakan untuk mengidentifikasi dan memeriksa faktor dominan yang mempengaruhi konsumen online untuk berbelanja online. Tabel 4 menunjukkan hasil nilai rata-rata dari faktor-faktor penting yang mempengaruhi konsumen online untuk berbelanja online (nilai 1 menjadi yang paling penting dan nilai 5 menjadi faktor yang paling penting): Berdasarkan hasil yang ditunjukkan pada Tabel 4, yang paling penting dan dominan faktor-faktor yang mempengaruhi konsumen online untuk berbelanja online adalah "kenyamanan" (3,91), "tidak bisa mendapatkan barang di tempat lain" $(3,91)$ dan "harga lebih murah" $(3,85)$.

Berdasarkan tinjauan literatur, berkaitan dengan konsep kerangka teoritis, hipotesis berikut dikembangkan: 1). H1: Tidak ada hubungan atau hubungan antara belanja online dan variabel demografis (lokasi geografis, jenis kelamin, ras, usia, status perkawinan, jumlah anak, tingkat pendidikan, profesi, pendapatan, kredit kartu dan periksa kepemilikan buku). 2). H2: Tidak ada hubungan atau hubungan antara belanja online dan pembelian barang dan jasa melalui toko fisik, katalog / pesanan surat, TV / telepon dan penjualan langsung melalui salesman. 3). H3: Tidak ada perbedaan antara pengguna dan nonpengguna belanja online dalam menggunakan situs web penjual online untuk mengumpulkan informasi produk dan membandingkan harga barang dan layanan. 4). H4: Tidak ada korelasi yang signifikan antara variabel pembelian online di masa depan (frekuensi pembelian, pembelanjaan online dan penjual online yang sama) dan area arus perhatian dari variabel pengguna belanja online (pengungkapan informasi pribadi, penerimaan e-mail yang tidak diminta, keamanan pembayaran menggunakan kartu kredit, transfer bank, kepercayaan pada penjual online dan kecukupan undangundang perlindungan pelanggan)

\section{HIPOTESIS PENGUJIAN DAN PEMBAHASAN}

Tujuan utama dari bagian penelitian ini adalah untuk menguji empat hipotesis yang dikembangkan sebelumnya sebagaimana dinyatakan dalam bagian tinjauan pustaka. Pearson Chi-square, Independent Samples T-test dan Pearson Correlation Matrix digunakan untuk menguji hipotesis dan hasil tes disajikan dan didiskusikan secara terpisah. Berasal dari Tabel 5, hasil uji Pearson Chi-Square menunjukkan bahwa ada hubungan yang signifikan atau hubungan antara belanja online dan ras, tingkat pendidikan, kartu kredit dan kepemilikan kartu ATM (di mana p-value kurang atau sama dengan 0,05). Di antara variabel demografi, pembayaran melalui transfer bank paling terkait dengan belanja online, dengan nilai p 0,009. Hubungan antara belanja online dan variabel demografis ini memengaruhi jumlah pengguna belanja online dengan cara berikut: a). Dalam Jenis Kelamin, Wanita adalah peserta belanja online tertinggi $(67,1 \%)$ dan paling terkait secara signifikan dengan belanja online dengan pvalue adalah 0,002. b). Dalam tingkat kategori pendidikan, lulusan universitas adalah pengguna belanja online tertinggi $(0,001$ p-nilai) diikuti oleh pemegang diploma $(0,212$ p-nilai $)$ dan sekolah menengah (0,242 p-nilai). c). Di antara konsumen online yang memiliki setidaknya transfer bank, $41,9 \%$ adalah pengguna belanja online dengan nilai p 0,009. d). Di antara konsumen online yang Cash on Delivery (COD), 43,8\% adalah pengguna belanja online dengan nilai p 0,011.

Variabel demografi lainnya ditemukan tidak signifikan dan karena itu tidak terkait atau terkait dengan belanja online. 
Tabel 4: Nilai rata-rata faktor yang mempengaruhi belanja online

\begin{tabular}{|lcc|}
\hline $\begin{array}{l}\text { Variables } \\
\text { Deviation }\end{array}$ & Mean & \\
& $N=250$ & $N=250$ \\
\hline Nyaman & 3.91 & 1.32 \\
Tidak Mendapatkan & 3.91 & 1.34 \\
Barang di temat lain & & \\
Harga Lebih Murah & 3.85 & 1.63 \\
Lainnya & 3.4 & 2,09 \\
Inovatif & 3.28 & 1.57 \\
Seleksi Lebih Luas & 2.75 & 1.09 \\
Kesesuaian & 2.74 & 1.26 \\
Jenis Barang / Jasa & 2.63 & 1.11 \\
Trendi & 2.62 & 1.28 \\
Barang Terbaru & 2.56 & 1.32 \\
Pelayanan yang Baik & 2.37 & 1.33 \\
Pengiriman Cepat & 2.28 & 1.17 \\
Hiburan / Kesenangan & 2.25 & 1.16 \\
Suasana Bagus & 2.14 & 0.9 \\
Kredibilitas & 2.14 & 1.15 \\
\hline
\end{tabular}

Table 5: Hasil uji chi-square Pearson antara belanja online dan demografi

\begin{tabular}{|lccc|}
\hline $\begin{array}{l}\text { Variabel Demografi } \\
\text { Sig. }\end{array}$ & Value & $d f$ & Asymp. \\
& & & (2-tailed) \\
\hline Jenis Kelamin & 11.766 & 1 & $0,013^{*}$ \\
Wanita & 7.432 & 1 & 0.245 \\
Pria & 8.132 & 4 & 0,056 \\
Usia & & & \\
Pendidikan & 10.721 & 1 & $0.001 *$ \\
Universitas & 1.56 & 1 & 0.221 \\
Diploma & 1,369 & 1 & 0,232 \\
Sekolah Menegah & 12.027 & 12 & 0.435 \\
Profesi & 13.665 & 10 & 0.176 \\
Penghasilan & 6.767 & 1 & $0,009 *$ \\
Transfer bank & 6.432 & 1 & $0,011 *$ \\
Cash On Delivery & Note: * Significant at 0.05 level $(2$-sided $)$ & \\
N &
\end{tabular}

Table 6: Hasil uji Pearson Chi-square antara belanja internet dan metode pembelian lainnya

\begin{tabular}{|lccc|}
\hline $\begin{array}{l}\text { Purchasing } \\
\text { Sig. }\end{array}$ & Value & $d f$ & Asymp. \\
Method & & & (2-tailed) \\
\hline Official Stores & 0.49 & 1 & 0.487 \\
Katalog/Mail Order & 0.987 & 1 & 0.342 \\
TV/Telepon & 10.751 & 1 & $0.001^{*}$ \\
Penjualan langsung & 3.039 & 1 & 0.076 \\
Melalui salesman & & & \\
\hline
\end{tabular}

Note: * Significant at 0.05 level (2-sided)

Pearson Chi-square digunakan untuk menguji validitas hipotesis kedua dan hasilnya ditunjukkan pada Tabel 6 di atas. Hasil penelitian menunjukkan bahwa ada hubungan dan hubungan yang signifikan antara online dan pembelian melalui TV / telepon (dengan p-value 0,001) dimana $71,4 \%$ konsumen online yang menggunakan TV / telepon sebagai metode pembelian barang dan jasa juga pengguna belanja online. Variabel lain ditemukan tidak signifikan. T-test sampel independen digunakan untuk membandingkan perbedaan rata-rata antara pengguna dan non-pengguna belanja online dalam menggunakan situs web penjual online untuk mengumpulkan informasi produk dan untuk membandingkan harga barang dan jasa.

\section{KESIMPULAN DAN SARAN}

\section{Kesimpulan}

Penelitian ini untuk menguji dan memahami karakteristik pengguna saat ini belanja online dan hubungannya dengan variabel demografi dan pola perilaku konsumen relevan lainnya dengan tujuan membangun target pasar untuk belanja online di Indonesia.

Tujuan berikutnya dari penelitian ini adalah untuk menetapkan preferensi pengguna belanja online dalam memilih penjual online. Temuan dari studi ini juga mengimplikasikan bahwa konsumen mencari harga yang lebih murah dan tawarmenawar ketika mereka berbelanja online, menjadikannya salah satu faktor dominan yang memotivasi konsumen online di Indonesia untuk berbelanja online. Temuan ini juga menunjukkan bahwa penjual online perlu memberikan harga yang kompetitif untuk produk mereka untuk menarik pembeli online ke situs web 
mereka dan mendorong mereka untuk membuat keputusan pembelian.

Akhirnya, penelitian ini adalah untuk mengidentifikasi dan memeriksa bidang utama yang menjadi perhatian dan masalah yang saat ini dihadapi oleh pengguna belanja online dan untuk menilai dampaknya terhadap pembelian online di masa depan. Hasil penelitian menunjukkan bahwa pengguna belanja online di Indonesia paling peduli dengan privasi dalam mengungkapkan informasi pribadi ke penjual online ketika mereka melakukan pembelian melalui Internet. Studi ini juga menemukan bahwa ada korelasi yang signifikan antara bidang-bidang yang menjadi perhatian dan masalah yang dihadapi oleh pengguna belanja online. Kekhawatiran ini ada pada pemeriksaan barang, kecukupan undang-undang perlindungan konsumen dan peraturan dan tingkat kepercayaan pada penjual online. Selain itu, temuan penelitian ini menunjukkan bahwa mayoritas pengguna belanja online di Indonesia tidak memiliki kepercayaan dan kepercayaan dalam menggunakan internet untuk membeli barang dan jasa. Ada juga kurangnya kesadaran di antara sebagian besar nonpengguna belanja online tentang manfaat yang dapat diperoleh melalui belanja online dibandingkan dengan saluran belanja tradisional lainnya.

\section{Saran}

Meskipun potensi pertumbuhan ecommerce ritel dan minat yang terus meningkat dalam belanja online di Indonesia, masih ada kurangnya pemahaman mengenai karakteristik pembeli online di Indonesia dan potensi dampaknya pemasaran pada konsumen. Hal ini terutama disebabkan oleh fakta bahwa belanja online agak baru di Indonesia dan baru mulai mengambil tempatnya sebagai saluran belanja alternatif bagi konsumen untuk berbelanja barang dan jasa. Konsep ritel yang baru muncul ini telah menarik minat penjual dan bisnis, lembaga keuangan, penyedia layanan telekomunikasi, pejabat pemerintah dan bahkan konsumen karena berdasarkan karakteristik uniknya. Belanja online memiliki potensi menjadi saluran belanja alternatif yang dominan dalam waktu dekat yang tidak dapat dengan mudah ditantang oleh metode ritel konvensional. Rekomendasi yang dapat berasal dari temuan penelitian disajikan dan dibagi menjadi tiga bagian, yaitu, untuk penjual online, Telkom Indonesia sebagai penyedia layanan telekomunikasi dan Internet utama di negara dan Pemerintah Indonesia. Berdasarkan temuan penelitian, disarankan agar penjual online mempertimbangkan untuk mengambil inisiatif berikut untuk meningkatkan peluang sukses mereka dalam bisnis ritel melalui Internet: Penjual online perlu memastikan bahwa proses belanja online di situs web mereka dirancang semudah, sederhana dan sedapat mungkin bagi konsumen online untuk berbelanja online. Situs web juga harus dirancang sedemikian rupa agar tidak membingungkan pembeli online potensial di Indonesia, yang mungkin tidak akrab dengan bentuk belanja baru ini. Dengan situs web yang mudah digunakan dan ramah pengguna, ini akan mendorong pembeli baru untuk membuat keputusan pembelian yang kemungkinan besar akan kembali untuk pembelian berulang. Penjua online juga perlu memastikan bahwa mereka menyediakan layanan pengiriman yang efisien kepada pelanggan mereka, terutama barang-barang yang dibeli untuk acaraacara khusus serta barang yang mudah rusak yang mudah rusak yang perlu dikirimkan ke pelanggan secara tepat waktu. Salah satu cara untuk mencapai hal 
ini adalah bagi penjual online untuk menyimpan persediaan barang yang cukup dan untuk menerapkan sistem pelacakan yang akan memungkinkan penjual daring maupun pelanggan untuk melacak dan mendapatkan informasi tentang status pengiriman barang. Namun, ini hanya dapat dicapai melalui penyederhanaan dan integrasi proses operasi bisnis penjual online saat ini dengan pemasok, gudang, dan perusahaan pengiriman mereka. Selain itu, ada juga kebutuhan bagi penjual online untuk mengembangkan kebijakan privasi yang komprehensif bagi pelanggan mereka tentang pengungkapan informasi pribadi untuk mengurangi kekhawatiran privasi mereka. Kebijakan tersebut harus dengan jelas menyatakan bahwa informasi yang dikumpulkan akan dirahasiakan dan tidak dibagikan atau diteruskan ke pihak lain tanpa persetujuan mereka. Juga harus ada jalan bagi pelanggan untuk meminta penghapusan informasi pribadi mereka dari basis data penjual online.

\section{DAFTAR PUSTAKA}

Asosiasi Penyelenggara Jasa Internet Indonesia (APJII) dan Pusat Kajian dan Komunikasi Universitas Indonesia (Puskakom UI). 2015. "Mayoritas Netizen di Indonesia Berusia 18-25 Tahun”. (online) http://www.beritasatu.com/iptek/261 297-mayoritas-netizen-di-indonesiaberusia-1825-tahun.html (diakses pada 17 Juli 2018 pukul 14.53)

Eastlick, M.A. and S. Lotz. 1999. "Profiling Potential Adopters and Non-Adopters of an Interactive Electronic Shopping Medium," International Journal of Retail \& Distribution Management, 27(6): 919.
GlobalWebIndex's biannual report on the latest trends in online commerce, Flaghip Report 2018, www.globalwebindex.com

Hanson, W. 1999. Principles of Internet Marketing. Ohio: South-Western College Publishing.

Hsin, T. H. 2000. Online shopping: A Fad or A Revolution. Retail Group Malaysia. Retail World Asia 2000, Yearly, May 11, 2000 p.25.

Legard, D. 1998. E-Commerce Boom Ahead for Malaysia. Computer World Hong Kong, April 3, 1998 p.3.

Louis, C. and M. L. Leon. 1999. Computimes: Evolving with Ecommerce, New Straits Times, Weekly, December 8, 1999 p.26.

Margherio, L. 1998. The Emerging Digital Economy. Secretariat for Electronic Commerce. Washington: US Department of Commerce.

Official Home Page of We are social: Digital In 2018: World's Internet Users Pass The 4 Billion Mark. Retrieved Juli 26, 2018, from <https://wearesocial.com/blog/2018/ 01/global-digital-report-2018>

Official Home Page of NUA Surveys. 2001. Retrieved May 20, 2018, from <http://www.nua.ie/surveys/ index.cgi?f=VS\&art_id=905357198 \&rel=true>

Organisation of Economic Cooperation Development (OECD). 1997. Dismantling the Barriers to Global Electronic Commerce. Paris: OECD, 1997.

Parsons, A.G. 2002. "Non-functional motives for online shoppers: Why we click," Journal of Consumer Marketing, 19(5): 25-39.

Peterson, R.A., S. Balasubramaniam and B. J. Bronnenberg. 1997. "Exploring the Implications of the Internet for Consumer Marketing," Academy of 
Marketing Science Journal, Greenvale, Fall edition.

Rowley, J. 2000. "Product Search in Eshopping: A Review and Research Propositions," Journal of Consumer Marketing, 17(1): 124-135.

Shannon, J. 1997. Sales Boost for Retailers on Net. Marketing Week London, December 11, 1997 p.17.

The Economist. 1997. The Once and Future Mall. The Economist, Monthly, November 1, 1997 p. 7678.

Wui, Y.W. 2000. Business Computing: Online Retail Environment Lacking in Malaysia, New Strait Times, Weekly, March 1, 2000 p.15.

Wyckoff, A. 1997. Imagining the Impact of Electronic Commerce. Organisation for Economic Cooperation and Development (OECD), Paris: The OECD Observer, Oct/Nov 1997.

Zwass, V. 1996. "Electronic Commerce: Structures and Issues," International Journal of Electronic Commerce, 1(1): 3 - 23 . 